\title{
Contribuições da formação inicial de professores no Programa Institucional de Bolsas de Iniciação à Docência (Pibid) para a educação ambiental
}

\section{Contributions of initial teacher education in the Institutional Teaching Initiation Scholarship Program (Pibid) for environmental education}

\section{Aportes de la formación inicial docente en el Programa de Becas de Iniciación Docente Institucional (Pibid) para la educación ambiental}

\author{
Izabelle Maria Nascimento de Rezende ${ }^{1}$ \\ Cirdes Nunes Moreira ${ }^{2}$ \\ Monica Lopes Folena Araújo ${ }^{3}$
}

\begin{abstract}
Resumo
A inserção da Educação Ambiental (EA) na formação de professores se revela como um exitoso caminho na busca pela implementação da mesma em todos os níveis, modalidades e instituições de ensino. E, neste sentido, o Programa Institucional de Bolsas de Iniciação à Docência (Pibid) se configura campo propício a estudos sobre formação de professores. No presente estudo, realizado no âmbito da Universidade Federal Rural de Pernambuco (UFRPE), objetivamos, de modo geral, compreender as contribuições da formação inicial de professores de Ciências e Biologia no Pibid para a prática docente da EA na educação básica. Recorremos à análise documental do subprojeto e relatórios de atividades de 2013, 2014 e 2015. A partir da aplicação da técnica de análise de conteúdo identificamos que a EA contribuiu para criticidade e reflexão a respeito de questões socioambientais. Palavras-Chave:Educação Ambiental. Formação Inicial de Professores de Ciências e Biologia. Programa Institucional de Bolsas de Iniciação à Docência.
\end{abstract}

\section{Abstract}

The insertion of Environmental Education (EE) in the training of teachers is revealed as a successful path in the search for its implementation at all levels, modalities and educational institutions. In this sense, the Institutional Teaching Initiation Scholarship Program (Pibid) appears to be a favorable field for studies on teacher education. In the present study, carried out within the scope of the Federal Rural University of Pernambuco (UFRPE), we aim, in general, to understand the contributions of the initial training of science and biology teachers in Pibid to the teaching practice of EA in basic education. We resorted to documentary analysis of the subproject and activity reports for 2013, 2014 and 2015. Based on the application of the content analysis technique, we identified that the EA contributed to criticality and reflection on socio-environmental issues.

Keywords: Environmental education. Initial Formation of Science and Biology Teachers. Institutional Program for Teaching Initiation Scholarships.

\section{Resumen}

\footnotetext{
1 Universidade Federal Rural de Pernambuco

2 Universidade Federal Rural de Pernambuco.

3 Universidade Federal Rural de Pernambuco.
} 
La inserción de la Educación Ambiental (EA) en la formación de docentes se revela como un camino exitoso en la búsqueda de su implementación en todos los niveles, modalidades e instituciones educativas. En este sentido, el Programa de Becas de Iniciación a la Docencia Institucional (Pibid) parece ser un campo propicio para los estudios sobre formación docente. En el presente estudio, realizado en el ámbito de la Universidad Federal Rural de Pernambuco (UFRPE), pretendemos, en general, comprender las contribuciones de la formación inicial de profesores de ciencias y biología en Pibid a la práctica docente de EA en educación básica. educación. Se recurrió al análisis documental del subproyecto y los informes de actividad de los años 2013, 2014 y 2015. Con base en la aplicación de la técnica de análisis de contenido, identificamos que la EA contribuyó a la criticidad y reflexión sobre temas socioambientales.

Palabras Clave: Educación ambiental. Formación Inicial de Profesores de Ciencias y Biología. Programa Institucional de Becas de Iniciación Docente.

\section{Introdução}

A formação para a cidadania é um compromisso ético e moral que norteia o exercício docente, por isso não faz sentido atuar como professor ou professora se não para possibilitar aos estudantes a construção de conhecimentos sobre si e suas realidades. É papel das instituições de ensino subsidiar esses sujeitos no aperfeiçoamento das suas visões de mundo, no enfrentamento de situações cotidianas reais e no agir socioambientalmente. Assim, julgamos ser importante que a formação dos estudantes possibilite a construção de um pensar complexo e multifacetado sobre a vida; e, sobretudo, auxilie à ação socioambientalmente responsável desses indivíduos no meio em que se inserem.

A questão da formação inicial de professores é um ponto de partida central para investigarmos os caminhos trilhados no trabalho com a EA nas diferentes modalidades e níveis de ensino. Por essas razões, concebemos a universidade como um espaço formativo inicial singular e motivador das inovações necessárias para que o sistema de ensino como um todo atenda às atuais demandas sociais e científicas.

Diante dessa importância da formação inicial de professores para a prática efetiva e exitosa da EA nas escolas fomos motivados a investigar a sua abordagem na Universidade Federal Rural de Pernambuco (UFRPE), instituição de referência e de tradição no Estado e na região Nordeste no campo da formação de professores, inclusive na abordagem da EA. Neste contexto, conhecemos o Programa Institucional de Bolsas de Iniciação à Docência (Pibid), que se constitui enquanto iniciativa pioneira nas licenciaturas, crescente em todo o país, mas que ainda tem sido estudado de forma pontual.

O Pibid na UFRPE é orientado pelo eixo "Ciência e Contexto", sendo assim, pensamos que EA pode integrar essa linha de formação docente do programa na instituição, pois, a EA objetiva formar cidadãos conscientes das complexas relações entre ciência e sociedade. Ademais, optamos especificamente por esse subprojeto Pibid da UFRPE porque ele objetiva promover um processo de ensino-aprendizagem inovador, pautado na investigação e na reflexão crítica da realidade; articulando sujeitos e contextos na dimensão pessoal, profissional e institucional da formação para a docência comprometida com o 
desenvolvimento do sistema educativo como um todo.

Definimos como questão de pesquisa norteadora deste estudo: Quais as contribuições da formação inicial de professores de Ciências e Biologia no âmbito do Pibid para a prática docente da EA na educação básica? Por conseguinte, objetivamos de forma geral compreender as contribuições da formação inicial de professores de Ciências e Biologia no âmbito do Pibid para a prática docente da EA na educação básica. Nossos objetivos específicos foram: analisar como o Pibid Biologia insere a EA na formação dos licenciandos bolsistas e identificar atividades de EA desenvolvidas pelos licenciandos bolsistas nas escolas.

Adotamos a abordagem qualitativa e realizamos uma pesquisa documental. Analisamos os relatórios de atividades e o subprojeto institucional do Pibid Biologia. Os dados que coletamos nesse processo foram interpretados por meio da utilização da técnica de análise de conteúdo, proposta por Bardin (1994).

Esperamos que este estudo contribua para o delineamento da formação inicial oferecida pelo Pibid, de forma a identificar lacunas, incentivar a busca pelo aperfeiçoamento das ações desenvolvidas naquele contexto, socializar as estratégias exitosas para o exercício da EA e refletir sobre as potencialidades e limitações atreladas à EA na formação docente ofertada no Programa Institucional de Bolsas de Iniciação à Docência.

\section{Formação inicial de professores no Pibid}

O Pibid é uma iniciativa para o aperfeiçoamento e a valorização da formação de professores para a educação básica. Por isso integra em um trabalho colaborativo licenciandos, professores formadores, professores da educação básica e escolas parceiras. Os projetos de trabalho do Pibid promovem a inserção dos estudantes das licenciaturas no contexto das escolas públicas desde a graduação para o desenvolvimento de atividades didático-pedagógicas sob orientação de um docente da licenciatura e de um professor da escola.

O referido Programa foi instituído no Brasil em novembro de 2007 , a partir de uma parceria entre o Ministério da Educação (MEC), a Coordenação de Aperfeiçoamento de Pessoal de Nível Superior (Capes) e o Fundo Nacional de Desenvolvimento da Educação (FNDE). O Pibid tem por finalidade fomentar a iniciação à docência, contribuindo para o aperfeiçoamento da formação de docentes em nível superior e para a melhoria da qualidade da educação básica pública brasileira (BRASIL, 2013). De acordo com a Portaria de $n^{\circ} 96$, de 18 de julho de 2013, que dispõe sobre o Regulamento do Pibid, os projetos apoiados financeiramente pela Capes no âmbito do programa são propostos por Instituições de Ensino Superior (IES) e desenvolvidos por grupos de licenciandos sob a supervisão de professores da educação básica e orientação das instituições formadoras de professores (BRASIL, 2013).

Estão habilitadas a submeterem projetos ao programa as IES públicas e privadas com ou sem fins lucrativos que possuam cursos de licenciatura aprovados pelo MEC e em 
funcionamento.

O projeto institucional, que está vinculado a um ou mais subprojetos das licenciaturas, deve ser desenvolvido em escolas da rede pública federal, estadual e/ou municipal. Os subprojetos contam com, pelo menos, cinco estudantes das licenciaturas, um coordenador de área e um supervisor. Nos projetos institucionais são descritos os objetivos, as ações planejadas e o eixo temático (caso haja) que norteia o Pibid naquela IES. Como orienta o Art. $2^{\circ}$ da Portaria $n^{\circ} 96$, o projeto institucional do Pibid e os subprojetos devem abranger diferentes características e dimensões da iniciação à docência, como:

[...] o estudo do contexto educacional envolvendo ações nos diferentes espaços escolares; o planejamento de ações coletivas e interdisciplinares na escola e em espaços não formais de ensino; a participação nas reuniões e atividades de planejamento do projeto pedagógico da escola; a análise do processo de ensino-aprendizagem; a leitura e discussão de referenciais teóricos contemporâneos educacionais para o estudo de casos didáticopedagógicos; o desenvolvimento, a aplicação e avaliação de estratégias didático-pedagógicas e instrumentos educacionais, incluindo o uso de tecnologias educacionais e diferentes recursos didáticos; a elaboração de ações no espaço escolar a partir do diálogo e da articulação dos membros do programa, e destes com a comunidade e a sistematização e registro das atividades em portfólio ou instrumento equivalente de acompanhamento das atividades do programa (BRASIL, 2013).

Por meio da unidade teoria-prática e através da parceria entre IES e escolas, o Pibid procura contribuir de forma substancial e diferenciada para a formação inicial e continuada de professores, buscando atender aos seguintes objetivos descritos no Artigo $3^{\circ}$ do Decreto $\mathrm{n}^{\circ} 7.219$, de 24 de junho de 2010 :

I - incentivar a formação de docentes em nível superior para a educação básica;

II - contribuir para a valorização do magistério;

III - elevar a qualidade da formação inicial de professores nos cursos de licenciatura, promovendo a integração entre educação superior e educação básica;

IV - inserir os licenciandos no cotidiano de escolas da rede pública de educação, proporcionando-Ihes oportunidades de criação e participação em experiências metodológicas, tecnológicas e práticas docentes de caráter inovador e interdisciplinar que busquem a superação de problemas identificados no processo de ensino-aprendizagem;

V - incentivar escolas públicas de educação básica, mobilizando seus professores como co-formadores dos futuros docentes e tornando-as protagonistas nos processos de formação inicial para o magistério; e 
$\mathrm{VI}$ - contribuir para a articulação entre teoria e prática necessárias à formação dos docentes, elevando a qualidade das ações acadêmicas nos cursos de licenciatura (BRASIL, 2010).

Ao tempo do estudo realizado, o Pibid vinha sendo ampliado nas instituições de ensino superior em todo o país. Este crescimento, segundo Santos (2013), afirmou-se como incentivo para a elevação da qualidade das escolas públicas, para a valorização do magistério e para a configuração da escola como protagonista no processo de formação dos licenciandos.

O Programa tem possibilitado a discussão sobre a formação de professores, sugerindo meios possíveis de reinventá-la. Mais que isso, como notamos nos eventos e periódicos científicos, o futuro professor tem desenvolvido desde a graduação pesquisas sobre a sua prática docente. Através do programa os licenciandos bolsistas têm sido inseridos no cotidiano das escolas.

Contudo, entendemos que o Pibid não é o único meio de (re)construção da formação de professores, mas é um dos caminhos de aproximação entre a escola e a formação docente ofertada nas instituições de ensino superior.

Como revela Nóvoa (2009) é fundamental que a formação esteja constituída dentro da profissão e tenha como referência o trabalho na escola. Sousa e Marques $(2013$, p. 111) complementam esta ideia quando afirmam que, "o Pibid representa uma diversificação na forma de pensar e fazer a formação docente". O programa propõe por meio da tríade ensino-pesquisa-extensão uma aproximação entre a teoria e a prática no processo de formação docente voltado para a cidadania, para a responsabilidade socioambiental, para a criticidade e emancipação dos sujeitos da prática pedagógica.

\section{Desenho metodológico}

Os estudos em EA envolvem a reflexão e a análise de uma realidade complexa dos sujeitos e requerem uma investigação pautada no contexto e nos significados dos dados coletados. Desta forma, pensamos que a abordagem qualitativa é a mais adequada aos objetivos propostos neste trabalho porque, como nos orientam Bogdan e Biklen (1994), na investigação qualitativa a fonte direta dos dados é o ambiente natural, no nosso caso, o contexto da formação inicial de professores no âmbito do Pibid Biologia da UFRPE.

Já em relação aos tipos de pesquisa, adotamos a pesquisa do tipo documental. Na pesquisa documental, definida por Oliveira (2005) "como aquela que recorre a fontes primárias de informação, ou seja, materiais que não sofreram tratamento analítico ou científico"; identificamos possíveis contribuições na formação dos futuros professores para a prática docente com a EA no subprojeto institucional e nos relatórios de atividades do Pibid da área de Biologia.

Elegemos como instrumentos de estudo a análise documental do subprojeto institucional do Pibid da área de Biologia e dos relatórios de atividades, produzidos pelas coordenadoras, de 2013, 2014 e 2015, pois no perído do estudo o Pibid já enfrentava 
dificuldades de recursos e investimentos que se intensificaram a partir de então. Entretanto, o subprojeto escolhido apresentava destaque nas escolas públicas parceiras e, ao tempo do estudo, os trabalhos desenvolvidos eram referência entre estudantes das escolas, professores tutores e licenciandos. A análise dos dados coletados foi realizada pela análise de conteúdo proposta por Bardin (1994).

O subprojeto Pibid Biologia da UFRPE iniciou suas atividades na Região Metropolitana do Recife (RMR) no ano de 2009 e em janeiro de 2016 era composto por vinte e seis licenciandos bolsistas e duas coordenadoras de área, estas últimas também professoras formadoras na UFRPE. O subprojeto estava vinculado a sete instituições de ensino da RMR, que oferecem os níveis fundamental e médio nas modalidades da educação regular, educação profissional técnica de nível médio e/ou educação de jovens e adultos.

Contribuições da formação inicial de professores para a prática docente da EA e temáticas socioambientais identificadas no subprojeto

Como descrito em nosso caminho metodológico, inicialmente realizamos a análise documental do subprojeto Pibid Biologia de 2013 em busca de possíveis contribuições da formação inicial promovida no programa para a prática docente da EA na educação básica. No documento identificamos a menção ao tema institucional do programa na UFRPE, Ciência e Contexto, onde se destaca a importância deste tema para o letramento científico dos licenciandos bolsistas.

Além disto, no referido documento é evidenciada a necessidade da relação entre o plano de trabalho dos bolsistas nas escolas e as demandas destas instituições da Educação Básica, No documento também é destacado como objetivo específico a necessidade da formação de professores reflexivos, pesquisadores e centrados nos desafios do exercício da docência. Neste contexto, a EA pode estar inserida como demanda atual necessária requerida pela escola. Diante das problemáticas socioambientais que temos vivenciado, a EA se apresenta como um caminho na busca pela superação de desafios diários como a fragmentação dos conhecimentos, a pouca aplicabilidade dos conhecimentos construídos nas escolas no dia a dia, na tomada de decisões ou no incentivo de mudanças de postura emergenciais necessárias perante às questões socioambientais do cotidiano.

Por estas razões, concordamos com Francisco-Junior e Zibetti (2011), quando sugerem que a mediação e a apropriação do conhecimento devem estar atreladas ao contexto social no qual se insere a escola, portanto, vinculadas aos seus usos sociais para superar a alienação dos sujeitos da prática pedagógica e da prática social. Neste sentido, os autores destacam as possíveis contribuições de programas como o Pibid para o acesso ao conhecimento contextualizado pelos futuros professores e estudantes da Educação Básica.

Daí porque entendemos a articulação entre o conhecimento científico e o conhecimento do cotidiano como outra importante contribuição para a prática docente com a EA; relação sinalizada no documento analisado. Como observamos no subprojeto, pensar em uma escola articulada e inevitavelmente vinculada à vida dos estudantes é também 
colaborar para a abordagem da EA na Educação Básica. Este deve, inclusive, ser um eixo estruturador do currículo nas escolas, como preconizam documentos oficiais como os Parâmetros Curriculares Nacionais e as Orientações Curriculares para o Ensino Médio.

Portanto, pensamos que se nos debruçarmos exclusivamente sobre o ensino de Ciências e Biologia, essa articulação entre a escola e o cotidiano é ainda mais necessária, visto que as diversas formas de vida são os objetos de estudo de tais disciplinas. Afinal, como e por que estudar a vida se não para compreender a nossa realidade, portanto, entender e solucionar questões do dia a dia?

Somando-se a isto, pensamos que a diversificação dos instrumentos e estratégias didáticas se faz necessária para facilitar a mediação do conhecimento e o processo ensinoaprendizagem. Nesta direção, identificamos que a ludicidade é um elemento privilegiado no subprojeto, que destaca a importância da motivação e do estímulo à aprendizagem, a partir de diferentes e inovadoras metodologias.

O documento também evidencia a necessária formação para a cidadania, a partir das contribuições de habilidades e competências desenvolvidas por meio de distintas estratégias didáticas de ensino-aprendizagem de Ciências e Biologia. De acordo com o subprojeto, esta formação cidadã deve estar pautada na solidariedade, na cooperação e na responsabilidade, evidenciando, assim, a preocupação do subprojeto com uma formação que pode estar atrelada à EA. Desse modo, segundo Carvalho (2008), a EA pode oferecer um ambiente de aprendizagem em seu sentido mais profundo, auxiliando na formação individual e social dos sujeitos porque pode instituir novas formas de ser, de compreender e de posicionar-se diante dos outros, de si mesmo e dos desafios que vivemos.

Assim, compreender e estruturar a formação de professores e estudantes sob o olhar da cidadania e do papel destes indivíduos no ambiente, consequentemente também na sociedade, pode significar contribuir para a prática docente com a EA; enfatizando a relação destes sujeitos consigo e com os outros seres, atentando inclusive para a formação humana dos componentes da prática pedagógica. Ao analisarmos este trecho do subprojeto, percebemos evidenciada a importância não só do ensino-aprendizagem de conceitos, mas também o desenvolvimento de procedimentos e atitudes que possibilitem o crescimento e amadurecimento dos estudantes e professores enquanto cidadãos críticos, reflexivos, esclarecidos e modificadores da realidade.

No documento é apontado como objetivo geral do subprojeto Biologia "promover um ensino de Ciências e Biologia que prepare professores e alunos para uma inovação conceitual, procedimental e atitudinal, tomando como referência a dimensão complexa inerente aos fenômenos biológicos estudados". Como destacado, é objetivo do subprojeto possibilitar a compreensão complexa no estudo de Ciências e Biologia, sugerindo a essencialidade da visão holística dos fenômenos e processos biológicos.

Já em relação às ações específicas planejadas no projeto, identificamos várias contribuições possíveis para a prática com a EA. A primeira que listamos objetiva promover a formação dos licenciandos para a elaboração de planos de aula, sequências didáticas e de 
projetos disciplinares e interdisciplinares; que podem inclusive estar relacionados a questões socioambientais, contribuindo para prática docente da EA.

Outra ação visa socializar experiências e pesquisas na área de Ensino de Ciências e Biologia em eventos científicos, revistas e capítulos de livros. Assim, compreendemos que estas oportunidades de socialização, tanto podem estar relacionadas a produções científicas que tratem da EA, quanto possibilitar o acesso a vivências e experiências neste campo socioambiental de estudo.

De forma semelhante, a terceira ação que pode contribuir para a prática docente sob esta perspectiva socioambiental objetiva desenvolver projetos sobre temas relevantes para a escola e a comunidade. Sendo assim, pensamos que as questões socioambientais e, especificamente a EA, poderão ser contempladas por esta ação, visto que são temas essenciais de discussão e inserção no contexto educacional que podem ser apontados como necessários pelos componentes das escolas.

O documento destaca como resultado comum a contribuição para a formação inicial de professores alicerçada no planejamento e vivência de práticas inovadoras $e$ interdisciplinares; e na articulação entre teoria e prática. Neste contexto, pensamos a prática docente com a EA como uma abordagem compósita, plural e continuamente inovadora, pois está imersa no cotidiano e requer um trabalho coletivo para uma compreensão totalitária das questões socioambientais que tanto nos inquietam. Como nos questiona Freire (1996), por que não discutir com os estudantes a realidade concreta a que se deve associar a disciplina cujo conteúdo se ensina? Por que não estabelecer intimidade entre os saberes curriculares fundamentais e a experiência social que eles têm como indivíduos? Este é um viés importante da indissociação teoria e prática que curiosamente está relacionado à EA, embora Freire não tenha mencionado a EA em suas obras. Pensamos que essa relação teoria-prática é até mesmo construir uma formação de professores no, com e para 0 ambiente, como referencia Carvalho (2008).

O subprojeto aponta como resultado comum a busca por melhorias nas escolas envolvidas e impactos socioambientais nas comunidades próximas a estas instituições, objetivando melhorar as condições socioambientais da comunidade escolar a partir dos projetos desenvolvidos. Assim, de acordo com trechos extraídos do documento: " 0 subprojeto visa produzir melhorias nas escolas envolvidas e impactos socioambientais nas comunidades próximas ao entorno das escolas", além das melhorias promovidas a partir das intervenções do programa, como mencionamos. O documento não esclarece que condições socioambientais seriam estas, mas notamos, a partir deste resultado pretendido, uma preocupação em apoiar a comunidade escolar e as comunidades próximas em seu progresso intelectual, material e imaterial.

Por fim, outra característica preferencial objetivada no subprojeto Biologia é a produção acadêmica científica e divulgação em eventos regionais e nacionais da área educacional, destacando nestes resultados a importância da pesquisa e da socialização científica na formação de professores. Como dissemos anteriormente, o estímulo e a 
preparação para a pesquisa em Educação e em Ensino de Ciências e Biologia podem ser importantes meios de contribuição para o trabalho com a EA nas instituições de Educação Básica.

Contribuições da formação inicial de professores para a prática docente da EA e temáticas socioambientais identificadas nos relatórios de atividades do Pibid

A preocupação com a formação para pesquisa e com a socialização dos trabalhos científicos também foi constatada na análise do relatório de atividades do ano de 2013 . Na categoria de atividades de produções bibliográficas verificamos várias ações relacionadas a temáticas socioambientais, entre elas podemos citar os resumos técnico-científicos, trabalhos de conclusão de curso defendidos (um deles tratou sobre as Contribuições de uma oficina de EA no processo ensino-aprendizagem numa escola pública do Município de Camaragibe, Pernambuco) e publicações de capítulos de livros a respeito de temáticas que muitas vezes incluíam questões socioambientais, tais como: a importância de uma alimentação equilibrada, conservação da biodiversidade, resíduos, doenças, entre outros assuntos.

Concordamos com Sousa (2013) quando nos fala sobre a importância de potencializarmos a pesquisa no contexto do Pibid, de modo que no Programa a escola é um espaço permanente de reflexão e investigação, reformulando inclusive o papel do professor como um ator que não só pensa o currículo, mas o modifica e reelabora constantemente suas ações. Por estas razões, Lima (2013) afirma que as experiências vivenciadas no Pibid contribuem efetivamente para o exercício da docência, visto que oportuniza aos licenciandos a construção de produções diversificadas, vivenciando muitos desafios e aprimorando competências e habilidades distintas.

Identificamos nos relatórios dos bolsistas que as diferentes atividades desenvolvidas no Pibid Biologia foram agrupadas em cinco categorias de acordo com a classificação proposta pela Capes, que divide as produções nos seguintes grupos: produções didáticopedagógicas (que incluíam planos de aula, projeto educacional, produção de roteiro de visitas, oficinas, minicursos, produção de apostilas, monitorias e sequências didáticas); produções bibliográficas (que abarcavam a divulgação e/ou publicação de trabalhos científicos e as participações em eventos); produções artístico-culturais (compreendiam a produção de mural com colagem e a construção de jogos); produções desportivas e lúdicas (continham as atividades relacionadas à prática de esportes), e produções técnicas de manutenção de infraestrutura e documentos (abrangiam a modificação de projetos pedagógicos e a manutenção do laboratório de ciências). Assim, optamos por analisar as contribuições das atividades realizadas, agrupando-as nas referidas categorias.

Na categoria de produções didático-pedagógicas que sistematizava as ações da área de Biologia em 2013, descritas no relatório de atividades daquele ano, o grupo elaborou planos de aula, projetos educacionais, sequências didáticas, monitorias, minicursos, apostilas, roteiros de visitas técnicas e oficinas. Verificamos nestas produções que 
temáticas socioambientais foram abordadas em várias delas, deste modo, temas como o uso responsável de recursos naturais como a água; a destinação adequada de resíduos; planejamento familiar e sexualidade; educação alimentar; e medidas preventivas contra doenças como Filariose, Síndrome da Imunodeficiência Adquirida (SIDA), Ascaridíase, Giardíase, entre outras. Para tratar dessas temáticas foram desenvolvidos cinco experimentos, dois jogos, três debates, dois júris simulados, um quiz, dois trabalhos em grupo e promovida a construção de quatro textos e murais pelos estudantes sobre os assuntos abordados.

Concordamos com Carvalho (2008) quando ela nos fala sobre a importância da reflexão sobre os nossos papéis como educadores, expectativas e intencionalidades. Na perspectiva de uma aprendizagem significativa, a intencionalidade pedagógica está na construção de novos sentidos e nexos para a vida, em que atividades, experiências, modos de fazer e informações estejam a serviço de formação de atitudes e não sejam um fim em si mesmos. Por isso, é fundamental que pensemos sobre que caminhos queremos seguir em nossa prática docente e que objetivos queremos alcançar por meio das intenções que permeiam a ação docente. Vimos no Pibid práticas que buscam esse despertar de atitudes, repletas de intenção para promover novos sentidos, olhares, novas visões diante de questões cotidianas. Os recursos didáticos foram também distintos nas categorias de produção que organizaram os relatórios analisados.

Como dissemos, diversas produções foram construídas em 2013, dentre elas as oficinas, últimas produções categorizadas nas atividades didático-pedagógicas, totalizando dezoito atividades deste tipo. Quatorze destas oficinas trataram de questões socioambientais. Os temas discutidos que nos revelam possíveis contribuições para a prática pedagógica com a EA foram: o uso de drogas; a sexualidade; a valorização das diversas formas de vida; medidas profiláticas contra doenças parasitárias; a importância ecológica e econômica dos vegetais; as relações entre alimentação e saúde; os impactos do lixo nas cidades; os impactos socioambientais nos diversos ecossistemas, a partir de problemática local que envolvia a construção de um shopping na cidade de Recife; planejamento familiar e métodos contraceptivos, bem como outras questões socioambientais inerentes à comunidade escolar e à RMR.

Já a respeito dos resultados artístico-culturais desenvolvidos no Programa, podemos citar a produção de um mural com colagens de animais invertebrados marinhos e terrestres e a construção de quatro jogos. O primeiro jogo foi intitulado "SIDA: conhecendo o nosso corpo" e aplicado com estudantes do $8^{\circ}$ e $9^{\circ}$ anos do Ensino Fundamental. A atividade foi composta por tabuleiros, tampinhas de garrafa PET (poli tereftalato de etila) coloridas e questões diversas sobre a doença, cuidados com a higiene íntima e os aparelhos reprodutivos humanos. O outro jogo construído pelos pibidianos foi intitulado "Montando crustáceos e aracnídeos" e objetivava avaliar os conhecimentos construídos sobre a morfologia animal. Já a terceira atividade lúdica, o "Jogo da memória parasitário", propôs que os estudantes do $7^{\circ}$ ano encontrassem as cartas com imagens de parasitas estudados e 
identificassem as respectivas características. O último deles, nomeado "Descobrindo as características dos diplópodes e quilópodes" objetivou consolidar os conhecimentos construídos sobre esses animais ao longo da oficina Invertzoo.

O uso de jogos é uma estratégia que pode ser muito positiva para o aprendizado, porque, como pontuam Nicollito e Campos (2013), o jogo promove o desenvolvimento da memória, linguagem, interação, atenção, percepção, e, principalmente, a aprendizagem. Ressaltamos, porém, que não necessariamente seu uso implicará na contribuição para abordagem da EA na prática pedagógica, mas sugere que a diversificação de recursos didáticos também é um importante elemento que poderá facilitar o tratamento de questões socioambientais nas escolas. Além disto, percebemos nos jogos elaborados que temáticas socioambientais foram priorizadas nas contruções destes recursos, podendo sinalizar possíveis contribuições para a prática docente com a EA. A prevenção de doenças, os cuidados com o corpo e a ampliação de conhecimentos a respeito dos seres vivos foram temas de expressivo interesse na realização de atividades e construção de materiais didáticos.

De forma semelhante, no relatório do ano de 2014, identificamos diversas atividades que possivelmente contribuíram para a prática docente com a EA, visto que a maior parte delas tratava de questões socioambientais como a geração e descarte de resíduos, o consumo responsável, os cuidados com o corpo e a prevenção de doenças, qualidade de vida, drogas, entre outras temáticas. Concordamos com Araujo (2013) quando ela nos fala sobre a intencionalidade de promover a inserção das questões socioambientais como um caminho motivador para a sensibilização, de modo a promover novas atitudes éticas em relação ao meio e valores como pertencimento e co-responsabilidade que permitam o desenvolvimento de um mundo mais justo e ambientalmente sadio. Diante dos resultados que encontramos na análise documental, e, posteriormente por meio das entrevistas, inferimos que esse é um objetivo que perpassa as ações formativas do Programa nas escolas e na Universidade no que tange a contribuição do Pibid para o desenvolvimento socioambiental dos contextos onde atua.

Vale salientar que as atividades descritas nos relatórios são referidas a partir de indicadores: cada atividade (ou conjunto de atividades realizadas por cada subprojeto) e suas produções deverão estar associadas a um indicador de atividade (número associado a um objetivo). Os objetivos do subprojeto Biologia da UFRPE foram semelhantes aos do subprojeto da Universidade Estadual de Ponta Grossa, no Paraná, descritos por Morales, Costa-Ayub e Nogueira (2013) que, em suma, visavam colaborar para o embasamento teórico-metodológico para as ações pedagógicas nas escolas; identificar os problemas da realidade educacional, bem como das condições de trabalho dos professores e supervisores; elaborar atividades para propor alternativas exitosas no processo de ensino-aprendizagem e divulgar, por meio de construções científicas, os resultados alcançados através desse trabalho formativo. Embora cada subprojeto tenha suas particularidades, em geral buscam auxiliar os futuros professores a vivenciarem a realidade da escola e a se prepararem para 
atender da melhor forma possível às demandas sociais e da escola requeridas no processo de ensino-aprendizagem.

A partir da análise do relatório de 2014 da área de Biologia da UFRPE identificamos também que o indicador de atividade de número um, que se refere à confecção de recurso didático para o ensino de Ciências e Biologia, expõe como resultado a construção de poemas para tratar problemas ambientais de forma lúdica e criativa, que culminou na confecção e publicação em 2015, pela Editora Universitária da UFRPE, de dois livros que reuniram os poemas escritos por estudantes do $9^{\circ}$ ano da Escola Dom Bosco.

Neste sentido, percebemos que a abordagem de questões socioambientais na prática docente é considerada importante e necessária, sobretudo atrelada à criatividade e à ludicidade. $\mathrm{O}$ documento menciona as sequências didáticas sobre temáticas socioambientais como aquecimento global, biodiversidade, plantas Angiospermas, relação entre qualidade do ar e saúde, insetos, sistema locomotor e evolução dos Anfíbios. Carvalho (2008) nos fala sobre a importância da participação da escola na inserção efetiva da EA para promoção de novas visões e incentivo ao desenvolvimento de atitudes mais responsáveis, conscientes e críticas diante das questões do nosso tempo. Por isso, pensamos que é no dia a dia da sala de aula, ao longo das atividades de todas as disciplinas que, aos poucos, a EA perpassa os conhecimentos específicos, dando a eles significado, a partir do momento que estes passam a ter relação com o cotidiano e as diversas realidades da comunidade escolar.

De forma semelhante, identificamos outro objetivo relacionado às temáticas socioambientais, listado no oitavo indicador de atividade, que teve como meta a elaboração de materiais didáticos disciplinares e interdisciplinares para atender às demandas da comunidade escolar. O relatório de 2014 pontua como produto deste objetivo a construção de tirinhas pelos estudantes da Escola Dom Bosco que tratavam sobre doenças sexualmente transmissíveis, de forma a discutir sobre os agentes patogênicos causadores das doenças e sobre a importância de medidas de prevenção, como a utilização de preservativo.

Concordamos com Leite (2004) quando ela nos fala que o professor deve conhecer o conteúdo e as estratégias para ensinar, assim, complementa e afirma que diante do novo cenário educacional contemporâneo é necessário que o futuro professor desenvolva e utilize estratégias de aulas que enfatizem as novas metas de aprendizagem requeridas pelo(s) novo(s) contexto(s) profisional(is) do presente. Por essas razões compreendemos de forma positiva a utilização de tirinhas, jogos, reportagens, documentários, filmes e poemas no Ensino de Ciências e Biologia.

Nesta direção, para atender ao décimo segundo objetivo listado no relatório de atividades do ano de 2014, qual seja, identificar e propor formas de utilização da sala de informática e dos recursos de ensino disponíveis nessa área, foram exibidos dois vídeos. $\mathrm{O}$ primeiro, intitulado "Ilha das Flores", visa promover uma reflexão a respeito de temas como alimentação, desperdício, consumo, dignidade humana e destinação de resíduos. Já o segundo, é o filme de nome "Lorax: em busca da trúfula perdida", que trata especificamente sobre meio ambiente e conservação ambiental. 
As temáticas socioambientais foram objeto de estudo nas atividades elaboradas no ano de 2014 que buscavam atender ao objetivo de realizar oficinas com temáticas relativas ao ensino de Ciências e Biologia. Verificamos que questões como a geração e a destinação adequada de residuos, bem como a relação entre o lixo e os vetores de doenças foram foco das discussões. Além destes temas, foram abordadas, ao longo das oficinas: as relações entre a alimentação e a saúde; a poluição do ar e as doenças respiratórias; e as doenças sexualmente transmissíveis e as medidas preventivas. Essas temáticas são semelhantes às apontadas por Morales, Costa-Ayub e Nogueira (2013) quando relatam as vivências construídas a partir das ações do projeto da área de Biologia da Universidade Estadual de Ponta Grossa no Paraná que tratou sobre temas como drogas, sexualidade, hortas, alimentação equilibrada e a relação entre a Botânica e o cotidiano.

Do mesmo modo, a respeito das produções didático-pedagógicas, foram elaboradas sequências didáticas que trataram de temas como poluição do ar, aquecimento global, riqueza ecológica vegetal, biomas e biodiversidade brasileira, alimentação e nutrição. No relatório constam também sequências que visaram especificamente, e de modo explícito, abordar a EA. Dentre estas podemos citar a sequência na qual foi exibido e discutido o filme "O dia depois de amanhã" para debate a respeito do aquecimento global; a realização da proposta didática intitulada "banquete sustentável" para discussão sobre educação nutricional; o diálogo com os estudantes sobre o consumismo e os seus impactos socioambientais a partir das problematizações sugeridas no vídeo "A história das coisas", que culminou com a construção de desenhos sobre o tema.

Como nos fala Leite (2004), a sólida formação teórica que o professor ou futuro professor precisam ter também abarca o desenvolvimento de habilidades que os auxiliem na escolha dos instrumentos mais adequados aos diversos temas para que sua sala de aula seja um espaço de debate, discussão, reflexão, questionamento e até mesmo especulações sobre assuntos do cotidiano. A diversificação, tanto das estratégias, quanto dos temas, é umas das características do trabalho formativo construído no âmbito do Pibid na UFRPE que também preza pela geração de produtos que podem inclusive auxiliar os estudantes no reaproveitamento de materiais do dia a dia ou minimização dos impactos ambientais negativos do consumo.

Sobre esses resíduos foram elaboradas duas oficinas. A primeira discutiu a respeito dos danos ambientais causados pelo descarte incorreto de óleo de cozinha e suas implicações para poluição do solo e da água. Ao final desta oficina os estudantes fabricaram sabão a partir do óleo de cozinha que seria descartado em suas casas. Já a outra oficina sobre resíduos abordou temas como o lixo, a importância da redução do consumo, da reciclagem e da reutilização; a sustentabilidade e a política nacional de resíduos sólidos. Como produtos desta oficina os estudantes das instituições parceiras construíram gibis ilustrando possíveis soluções para a problemática dos resíduos e fizeram peças artesanais através da reutilização de produtos do cotidiano. Foi promovida ainda uma oficina sobre recicagem a partir da confecção de papel machê. 
Somando-se a isto, os estudantes da Educação Básica foram também convidados a refletir a respeito de questões socioambientais locais que integram o seu cotidiano. Assim, duas oficinas tiveram este intuito: a "Cantando o ambiental", que relacionava a música às problemáticas ambientais e uma oficina sobre Ecologia que buscou sensibilizar sobre a importância dos cuidados com o ambiente através da realização de júri simulado, debate, análise de filme e passeata no entorno na escola.

Percebemos nessas ações o enfoque da EA crítica que, de acorco com Layrargues (2004), situa historicamente e no contexto as relações entre a sociedade e a natureza não humana a partir da possibilidade de mudança social por meio da mobilização dos sujeitos, inclusive dos componentes da prática pedagógica. Para Ghedin e Franco (2008) o olhar de educadores e educandos há de ser crítico e a crítica surge com a dúvida que questiona o modo pelo qual as coisas se apresentam. Questionar a realidade é papel da escola, por isso, deve-se educar o olhar para a criticidade, caso contrário, corre-se o risco de reproduzir apenas as representações do mundo e não o mundo em sua concretude, transformado pela arte de fazê-lo humano.

Além destes temas que objetivaram o estímulo à criticidade, os licenciandos também promoveram campanhas de sensibilização para prevenção e diagnóstico precoce dos cânceres de mama e próstata, esclarecendo como funciona a doença e alertando a respeito dos seus riscos por meio de iniciativas como o "Outubro Rosa" e o "Novembro Azul". Essas ações evidenciam a compreensão de homem como ambiente, na qual o nosso corpo é entendido também como ambiente ao passo que na dimensão biológica, física, psicológica, espititual, cultural e tantas outras, relaciona-se e se interage interna e externamente com outros elementos. Ao mesmo tempo que muda é transformado, constitui o ambiente e é por ele constituído. Estamos e somos ambiente, sendo assim, cuidar do nosso corpo é também proteger o ambiente. Essas ações também promoveram e contribuíram para a inserção da EA na prática docente.

Dentre as produções bibliográficas, identificamos a construção de sete resumos que sugerem possíveis contribuições para a prática docente com a EA e que trataram sobre as concepções de estudantes sobre a problemática socioambiental do aquecimento global, discutiram as experiências vivenciadas em uma oficina sobre papel machê e analisaram a construção de poemas socioambientais na mesma escola.

O desenvolvimento das perspectivas de professor pesquisador e professor reflexivo é essencial para o amadurecimento profissional e crescimento da Ciência no campo educacional. Ancoradas em Leite (2004, p. 82), vimos que é importante que o professor "considere a pesquisa e os estudos sobre ensino e aprendizagem, e no ensino e na aprendizagem, como vitais para o seu aperfeiçoamento profissional". É também na socialização dos estudos que o professor tem a oportunidade de compartilhar experiências, aprender a partir da vivência de outros profissionais e tomar novos rumos na pesquisa e prática docente.

No ano de 2015 essa contribuição do Pibid para pesquisa também foi significativa, 
foram publicados os dois livros sobre poemas socioambientais, como mencionamos, e divulgados em eventos locais e regionais resumos e artigos que trataram sobre biopirataria, ludicidade, concepções de EA, concepções dos estudantes da Educação Básica sobre o lixo e modelos didáticos para o ensino de Fisiologia Humana.

A respeito das produções artístico-culturais relacionadas à EA, observamos no relatório de 2015 que os estudantes do $9^{\circ}$ ano do Ensino Fundamental e $1^{\circ}$ ano do Ensino Médio construíram tirinhas ilustrativas sobre doenças transmitidas por vetores atraídos pelo lixo e resenha crítica reflexiva a partir da orientação dos licenciandos e supervisora em uma das escolas parceiras.

As oficinas desenvolvidas em 2015 discutiram diversos temas socioambientais e propuseram a diversificação de instrumentos de ensino. Podemos citar entre estes temas a promoção de oficinas que trataram sobre as relações entre a engenharia genética e a melhoria da qualidade de vida dos indivíduos; a alimentação e a saúde feminina na semana temática "Rosa e Lilás", abordando alimentos benéficos e prejudiciais, bem como os distúrbios alimentares que afetam à sociedade na atualidade.

Ocorreram debates sobre algumas doenças da contemporaneidade decorrentes do modo de vida da maioria da população nas últimas décadas. A questão do lixo foi alvo das discussões nas oficinas em escolas que apresentavam esta problemática de modo que os estudantes construíram cartazes e charges sobre o tema em um trabalho interdisciplinar entre o Pibid Biologia e o subprojeto da área de História. O Pibid promoveu trilhas ambientais interpretativas para conhecimento e valorização de espécies vegetais em seus aspectos históricos, culturais, biológicos e econômicos. A alimentação equilibrada, a partir da proposição e capacitação para o desenvolvimento de hortas e composteiras, também foi abordada ao longo daquele ano. Os licenciandos desenvolveram inclusive uma peça teatral para debater a respeito dos principais distúrbios alimentares que afetam à população.

Outras atividades promoveram o estudo e prevenção de doenças causadas por vírus, por exemplo, a partir do uso de instrumentos lúdicos como palavras cruzadas, cartazes e mapas conceituais. A ludicidade foi priorizada ao longo dos trabalhos formativos desenvolvidos. Assim como a EA, posta como tema central para a realização das atividades no âmbito do programa, inclusive nos estudos teóricos promovidos nas reuniões formativas. Daí porque, foi ofertada uma formação específica para o estudo teórico da EA críticohumanizadora na qual os licenciandos tiveram a oportunidade de discutir e refletir sobre conceitos, pesquisas e experiências com EA a fim de superar possíveis lacunas formativas existentes e os auxiliar no desenvolvimento de ações socioambientais nas escolas.

A diversificação dos instrumentos e a inovação metodológica foram pontos norteadores dos trabalhos em 2015, por isso vimos que os licenciandos utilizaram cordéis para o estudo do sistema cardiovascular, enfocando a importância da doação de sangue e dos cuidados com a saúde do corpo e as relações entre movimento, prática de atividade física, circulação sanguínea e o funcionamento equilibrado do sistema cardiovascular e sistema locomotor. Os licenciandos construíram jogos com materiais de baixo custo, 
utilizaram reportagens para debate na sala de aula e orientaram a construção de mapas conceituais e tirinhas sobre outros temas socioambientais como bioética e doenças sexualmente transmissíveis.

Como podemos perceber as contribuições para o trabalho com a EA são diversificadas e auxiliam tanto na inserção da EA na prática docente, voltada sobretudo para formação cidadã, quanto em pesquisas sobre esta prática. Esses objetivos revelam indícios de uma EA crítica, como esclarece Carvalho (2008), que valoriza a atuação social dos sujeitos, a tomada de consciência e a participação dos mesmos na compreensão da realidade e transformação dos modelos socioambientais vigentes.

\section{Considerações finais}

Ao longo deste estudo constatamos que a EA perpassa de modo efetivo a formação inicial de professores desenvolvida no subprojeto Biologia da UFRPE. Vimos que as questões socioambientais são foco das discussões promovidas no âmbito do programa de forma diversificada e contínua, porque a EA é abordada em diversas temáticas por meio de instrumentos distintos como jogos didáticos, poemas, debates, vídeos, júri simulado, cartazes, leitura e construção de trabalhos acadêmicos.

Esperamos que este estudo motive a continuidade da investigação por outros professores inquietados pela EA e pela formação de professores. Como dissemos, pensamos que muitas conquistas ainda serão necessárias para (re) construir e (re) formular a formação de professores de acordo com as demandas das escolas, das instituições de formação inicial de professores e sociedade, mas, sem dúvida, o Pibid é um passo necessário nessa caminhada. Desejamos que os acertos e erros do programa motivem, espelhem e guiem as reformas nas instituições para que os estudantes das licenciaturas tenham acesso à uma formação inicial coerente com as necessidades formativas para a docência.

Mais que para a formação científica, nossas escolas precisam colaborar para a construção de sujeitos críticos, pensantes, responsáveis, solidários, humanos; voltada para uma formação integral e integrada ao meio que nos circunda, onde busquemos o sentimento de pertencimento ao meio e cuidado consigo e com o outro. Para tanto, como não considerar e lutar pela transversalização da EA na formação de professores e nas escolas? Nessa trajetória, buscaremos enquanto professores e pesquisadores fazermos da EA um guia orientador do nosso trabalho a fim de investigarmos e socializarmos iniciativas que contribuam de modo significativo para inserção contínua da EA.

\section{Referências}

ARAUJO, Maria Inêz Oliveira. Educação superior, turismo e interculturalidade: um novo olhar da educação para uma nova cultura. In: BAEDER, Angela Martins et al. Perspectivas de educação ambiental no constructo da interculturalidade. São Cristóvão: Editora UFS, 2013, p. 157 a 169. BARDIN, Laurence. Análise de conteúdo. Lisboa: Edições 70, 1994. BOGDAN, Robert; BIKLEN, Sari Knopp. Investigação qualitativa em educação. Porto: Porto Editora, 
1994.

BRASIL. Decreto ${ }^{\circ} 7.219$, de 24 de junho de 2010. Dispõe sobre o Programa Institucional de Bolsa de Iniciação à Docência - Pibid e dá outras providências. Brasília, 2010. Disponível em:

$<$ http://www.planalto.gov.br/ccivil_03/_ato2007-2010/2010/Decreto/D7219.htm>. Acesso em: 29 jun. 2013.

BRASIL. Portaria $n^{\circ}$ 096, de 18 de julho de 2013. Dispõe sobre o regulamento do Programa Institucional de Bolsa de Iniciação à Docência. Brasília, 2013. Disponível em: $<$ http://www.capes.gov.br/images/stories/download/legislacao/Portaria_096_18jul13_AprovaR egulamentoPIBID.pdf $>$. Acesso em: 05 jun. 2014.

CARVALHO, Isabel Cristina Moura. A formação do sujeito ecológico. 3. ed. São Paulo: Cortez, 2008. FRANCISCO JUNIOR, Wilmo Ernesto; ZIBETTI, Marli Lúcia Tonatto. Pibid- novos ou velhos espaços formativos? Perspectivas para a formação docente em Rondônia e no Brasil. São Carlos: Pedro \& João Editores, 2011.

FREIRE, Paulo. Pedagogia da autonomia: saberes necessários à prática educativa. 22. ed. Rio de Janeiro: Paz e Terra, 1996.

GHEDIN, Evandro; FRANCO, Maria Amélia Santoro. Questões de método na construção da pesquisa em educação. São Paulo: Cortez, 2008.

LAYRARGUES, Philippe Pomier. Identidades da educação ambiental brasileira. Brasília: Ministério do Meio Ambiente, 2004.

LEITE, Maria Alba. Formação docente: ciência e biologia - estudo de caso. Bauru: EDUSC, 2004.

LIMA, Cristina Trajano. As angústias e inquietações no processo de formação docente inicial. In: CAPPELLETTI, Neide Keiko Kravchychyn; MARTINIANK, Vera Lúcia; SANTOS, Sydione. Docência, reflexão e investigação no percurso de formação inicial. Ponta Grossa: Editora UEPG, 2013, p. 181 a 193.

MORALES, Angélica Góis, COSTA-AYUB, Cristina Lúcia Sant'Ana; NOGUEIRA, Mellisa de Souza Nogueira (Orgs.). Aproximação entre universidade e escola na formação de professores de biologia. Ponta Grossa: Editora UEPG, 2013.

NICOLITTO, Mayara Cristina; CAMPOS, Graziela Vaneza de. A Importância das atividades lúdicas no processo de alfabetização nos anos iniciais do Ensino Fundamental. In: CAPPELLETTI, Neide Keiko Kravchychyn; MARTINIANK, Vera Lúcia; SANTOS, Sydione. Docência, reflexão e investigação no percurso de formação inicial. Ponta Grossa: Editora UEPG, 2013.

NÓVOA, António. Para uma formação de professores construída dentro da profissão. Revista Educacion, Lisboa, n. 350, 2009. Disponível em:

<http://www.revistaeducacion.mec.es/re350/re350_09por.pdf>. Acesso em: 10 jan. 2014.

OLIVEIRA, Maria Marly de. Como fazer pesquisa qualitativa. Recife: Bagaço, 2005.

SANTOS, Sydione. Formação acadêmico-profissional e iniciação à docência: outros olhares, novas possibilidades. In: CAPPELLETTI, Neide Keiko Kravchychyn.; MARTINIANK, Vera Lúcia; SANTOS, Sydione. Docência, reflexão e investigação no percurso de formação inicial. Ponta Grossa: Editora UEPG, 2013, p. 23 a 38. 
SOUSA, Maria do Carmo. Quando universidade e escola vivenciam atividades compartilhadas na iniciação à docência: reflexões sobre as barreiras ou forças impeditivas da parceria colaborativa. In: SOUSA, Maria do Carmo; MARQUES, Clélia de Paula. Formação inicial de professores: parceria universidade-escola na formação de licenciandos. Curitiba: Appris, 2013.

SOUSA, Maria do Carmo; MARQUES, Clélia de Paula. Formação inicial de professores: parceria universidade-escola na formação de licenciandos. Curitiba: Appris, 2013.

\section{Izabelle Maria Nascimento de Rezende}

Mestra em Ensino das Ciências e Matemática e Licenciada em Ciências Biológicas pela Universidade Federal Rural de Pernambuco (UFRPE), Professora Efetiva na Rede Pública de Ensino de Pernambuco. E-mail: profa.izabellerezende@gmail.com. ORCID: https://orcid.org/0000-0002-3479-8060.

\section{Cirdes Nunes Moreira}

Doutor em Ensino das Ciências e Matemática, Mestre em Extensão Rural e Desenvolvimento Local, Engenheiro Agrônomo do Departamento de Educação (DEd) da Universidade Federal Rural de Pernambuco (UFRPE), Membro do Grupo de Pesquisa em Formação e Prática Pedagógica de Professores de Ciências e Biologia (FORBIO) e da Cátedra Paulo Freire da UFRPE. E-mail: cirdesnm@gmail.com. ORCID: https://orcid.org/0000-0002-8448-7076.

\section{Monica Lopes Folena Araújo}

Pós-doutorada em Educação pela Universidade Federal de Sergipe, Doutora em Educação pela Universidade Federal de Pernambuco, Mestra em Ensino das Ciências e Matemática pela Universidade Federal Rural de Pernambuco (UFRPE), Licenciada em Ciências Biológicas pela Universidade Federal do Rio de Janeiro, Professora do Departamento de Educação da UFRPE, Professora do Programa de Pós-Graduação em Ensino das Ciências da Universidade Federal Rural de Pernambuco, Coordenadora da Cátedra Paulo Freire da UFRPE e Membro do Grupo de Pesquisa em Formação e Prática Pedagógica de Professores de Ciências e Biologia (FORBIO) da UFRPE. E-mail: monica.folena@gmail.com. ORCID: https://orcid.org/0000-0002-0688-9782.

Recebido em: 07/07/2021

Aprovado em: 09/07/2021

Publicado em: 30/07/2021 